\title{
PRÁTICAS (MULTI)LETRADAS EM UM CURSO DE ARTE E MÍDIA
}

\author{
Cristiani Pereira de Morais Gonzalez* \\ Rossana Delmar de Lima Arcoverde**
}

\begin{abstract}
Resumo: A ocorrência de práticas de letramento, na cultura escrita, é incontestável e merece ser relida sob a ótica dos multiletramentos. Seguindo tal premissa, adotamos os novos estudos sobre o letramento e a teoria dos multiletramentos como aporte teórico (STREET, 2010; 2012; 2014; ROJO, 2009, 2012; 2013). Este artigo apresenta uma análise de práticas (multi)letradas vivenciadas por alunos de uma disciplina do Curso de Bacharelado em Arte e Mídia de uma universidade pública. O estudo tem como objetivo investigar essas práticas observadas em duas aulas. A análise revelou que o uso do celular, transgredindo as relações convencionais, viabilizou variedades de linguagens e de mídias, e mostrou práticas que constituíram os alunos em autores de produções individuais e coletivas.
\end{abstract}

Palavras-chave: Multiletramentos. Novos Estudos de Letramento. Práticas de (Multi)Letramentos.

\begin{abstract}
The existence of literacy practices in the written culture is undeniable and worth rereading from the perspective of Multiliteracies. Following this premise, this paper presents an analysis of (multi)literacy practices experienced by students in a discipline of the Major in Art and Media of a public university aiming to investigate the practices observed in two classes. For this, it adopted the New Literacy Studies and the theory of Multiliteracies as the theoretical framework (STREET, 2010, 2012; 2014; ROJO, 2009, 2012; 2013). Therefore, the analysis revealed that the use of cell phone, transgressing the conventional relations, enabled varieties of languages and media and showed practices that constituted the students as authors of individual and collective productions.
\end{abstract}

Keywords: Multiliteracies. New Literacy Studies. (Multi)literacies Practices.

\section{Introdução}

Os seres humanos, constante e diariamente, concretizam práticas de letramento e se envolvem em "[...] modos particulares de pensar sobre a leitura e a escrita e de realizá-las em contextos culturais" (STREET, 2012, p. 77), que dizem não só sobre o que fazem, como atestam sobre quem são (sua cultura!), e o que enunciam, para além de suas ações e valores.

A ocorrência dessas práticas de letramento, na cultura escrita, é incontestável, como salientaram os novos estudos sobre o letramento (NLS), e tem-se tornado fulcral numa concepção de letramento ideológico, no qual a multiplicidade e a ideologia são constituintes da sociedade e de seus sujeitos.

Sendo assim, não se justifica dizermos, como postula o letramento autônomo, que nosso letramento é igual, posto que "[...] o letramento varia. [...] As pessoas podem estar envolvidas em uma forma e não outra, suas identidades podem ser diferentes" (STREET, 2010, p. 37).

Sabido isso, convém refletirmos não sobre a (in)existência de práticas de letramento (ponto pacificado para nós!), mas sobre algumas práticas de letramento contemporâneas, marcadamente da cultura digital.

Como menciona Lopes (2013, p. 18), o mundo passou por “[...] mudanças avassaladoras de natureza econômica, política, tecnológica, cultural e social [...]", que caracterizam o que o autor denomina "modernidade recente". Nessa modernidade recente,

\footnotetext{
* Mestranda do Programa de Pós-Graduação em Linguagem e Ensino na Universidade Federal de Campina Grande (UFCG). Endereço eletrônico: cristianipmorais@gmail.com

** Doutora em Linguística Aplicada e Estudos da Linguagem pela PUC/SP. Professora da Universidade Federal de Campina Grande. Endereço eletrônico: rossanaarcoverde@uol.com.br
} 
[...] a linguagem, os textos, as línguas e as pessoas movem-se, cada vez mais, em sociedades hipersemiotizadas, o que tem levado a pensar as línguas, a linguagem e quem somos no mundo social em outras bases. (LOPES, 2013, p. 18-9).

Assim, entendemos que as práticas de letramento devem ser pensadas sob as bases da teoria dos multiletramentos, haja vista esta abarcar dois tipos específicos de multiplicidades presentes e fundantes na/da sociedade atual: a multiplicidade de linguagens e a diversidade de culturas.

Considerando, então, esse viés teórico e visando delimitar o objeto observacional do presente trabalho, voltamos nosso olhar ao campo da pesquisa que desenvolvemos na disciplina "Laboratório de Vídeo I" do Curso de Bacharelado em Arte e Mídia de uma instituição pública do Estado da Paraíba, levantando a seguinte questão norteadora: Que práticas (multi)letradas são vivenciadas pelos alunos dessa disciplina?

Para os fins deste estudo, objetivamos investigar as práticas (multi)letradas vivenciadas por esses alunos. Para dar conta de nosso intento na pesquisa, buscamos identificar essas práticas vivenciadas no contexto investigado e analisá-las sob a perspectiva teórica dos multiletramentos. Visando alcançar os fins referidos, procedemos a uma pesquisa de natureza qualitativa e de abordagem etnográfica, valendo-nos, ainda, da técnica da observação direta.

Permanecemos por quase dois meses inseridos na sala de aula da disciplina acima referida, gravando em áudio as falas dos sujeitos, fazendo anotações de campo e aplicando questionários.

O desenvolvimento deste artigo está organizado em três tópicos, além desta Introdução. No primeiro, apresentamos as bases teóricas que fundamentam o estudo realizado, buscando discorrer sobre os letramentos e seus principais conceitos. No tópico seguinte, expomos os caminhos metodológicos da investigação e esboçamos nossos primeiros achados que identificam, em especial, os sujeitos e suas práticas de letramentos no contexto da sala de aula. Prosseguindo, no terceiro tópico, discutimos sobre o uso do celular (prática constatada na sala de aula estudada) sob a ótica dos multiletramentos. Por fim, apresentamos algumas considerações finais.

\section{Das práticas letradas às práticas multiletradas: um enfoque teórico}

Durante a pesquisa que realizou no Irã, na década de $1970^{1}$, Street deparou-se com uma visão tradicional de letramento, exposta nos dizeres dos professores das escolas públicas, de que a vila era primitiva, e nas falas dos amigos da Universidade, de que os moradores das vilas iranianas eram bi-savoid (sem conhecimento). Esta situação, aos olhos de Street, era, no mínino, estranha, pois não se coadunava com o que ele via e pensava sobre as potencialidades observadas daquele povo. E, acreditando nisso, ele afirmava: “[...] há muito letramento acontecendo [...]" (STREET, 2010, p. 35).

Inconformado então com o pensamento corrente sobre o letramento, fundado na ideia de que as pessoas analfabetas seriam cognitivamente inferiores, Street envolveu-se em um conjunto alternativo de conceitos teóricos que ficaram conhecidos como "novos estudos sobre

\footnotetext{
${ }^{1}$ Segundo palavras de Street (2010, p. 34), "Na década de 1970, fui ao Irã. Não fui lá por questões de letramento, mas para pesquisar questões sobre o processo de migração. [...] Mas, [...] comecei a prestar atenção em algumas práticas que envolviam a escrita $[\ldots]$ ”.
} 
o letramento", para os quais o letramento seria conceituado sob o viés antropológico. A propósito disso, Soares (2010, p. 56) observa que,

do ponto de vista antropológico, letramento são as práticas sociais de leitura e escrita e os valores atribuídos a essas práticas em determinada cultura. Sob esse ponto de vista, ora se analisam diferenças culturais entre culturas letradas e não letradas, como faz Goody, ora identifica-se o caráter ideológico que permeia o estabelecimento dessas diferenças - o representante aqui é, claro, Brian Street, que realizou [...] uma "revolução conceitual nos estudos antropológicos do letramento, a partir de seu livro seminal Literacy in Theory and Practice (1984), revolução que vem progredindo e se aprofundando com os New Literacy Studies". [...] (SOARES, 2010, p. 56, grifo nosso).

Nessa corrente teórica, Street distinguiu o letramento sob a perspectiva de dois enfoques, o autônomo e, outro, denominado de ideológico. No modelo autônomo, presume-se que letramento pode ser reconhecido nas habilidades técnicas de uso da leitura e da escrita que os indivíduos fazem como se fosse algo que produz efeitos em suas vidas, independente dos contextos sociais e culturais em que vivem.

Esse modelo autônomo, por exemplo, é retratado nos julgamentos atribuídos aos moradores das vilas iranianas, tidos como analfabetos, isso porque é enfatizado, nessas avaliações, a hierarquização (com a consequente sobreposição de um sobre o outro) entre o letrado e o não-letrado, bem como a supervalorização do conhecimento escolar. Dessa maneira, para vários lugares, um só letramento era reconhecido e aceito como uma consequência única do desenvolvimento pessoal e social dominante, constituindo, inclusive, um modelo classificatório dos indivíduos, dividindo-os entre os que têm letramento e os que não têm.

No entanto, o letramento varia e cada sujeito pode possuir o seu, imbuído de sua natureza social, cultural e histórica. E, nessa seara de reconhecimento de pluralidades de letramentos, o modelo ideológico é entendido como todos aqueles processos de leitura e escrita observados, não apenas pela diversidade de modelos culturais, mas também pela natureza ideológica. Pressupõe, portanto, a ideia de que acontecem sempre envolvidos em relações de poder.

Como destaca Street (2014), é preciso focalizar esse caráter ideológico do letramento, levando em conta as variedades de letramento existentes em distintos contextos sociais e culturais, tendo em vista que se trata de modelos poderosos e que podem acarretar consequências diversas.

Feita essa primeira distinção, importa adentrarmos na diferenciação entre eventos de letramento e práticas de letramento - dois outros termos-chave para a compreensão dos NLS.

O termo "evento de letramento" "[...] deriva da ideia sociolinguística do 'evento de fala" (STREET, 2012, p. 74) e pode ser conceituado como "[...] atividades particulares em que o letramento tem um papel: podem ser atividades regulares repetidas" (BARTON apud STREET, 2014, p. 18). Entendemos, por assim dizer, que, nessas atividades, há letramento suficiente e se torna possível o reconhecimento de um evento pelos aspectos peculiares que podem ser descritos. Eventos de letramento são, assim, usos visíveis da escrita e da leitura.

As "práticas de letramento", por sua vez, podem ser definidas como "[...] modos culturais gerais de utilização dos letramentos aos quais as pessoas recorrem num evento letrado" (STREET, 2014, p.18). Nesse sentido, a noção de práticas traz à tona a ideia de padrões de atividades nesses eventos, os quais, para Street (2010), carregam significados aos participantes, ficando demonstrado que 
[...] o conceito de práticas de letramento distancia-se do contexto imediato em que os eventos ocorrem, para situá-los e interpretá-los em contextos institucionais e culturais a partir dos quais os participantes atribuem significados à escrita e à leitura, e aos eventos de que participam. (STREET; CASTANHEIRA, 2015).

As práticas de letramento, perceptivelmente, ultrapassam "o visto" e abarcam os usos e seus significados. A título de exemplo, podemos dizer que a palestra representa um clássico evento de letramento, no qual várias poderão ser as práticas de letramento vivenciadas.

Compreendidas as ideias principais dos novos estudos sobre o letramento, devemos, até por necessidade de adequação à conjuntura atual, ultrapassar a compreensão de "letramentos" para alcançar a de "multiletramentos".

Surgida no final do século XX (1996), com o Grupo de Nova Londres (GNL), a teoria dos multiletramentos desenvolveu-se, no Brasil, no século XXI (principalmente nesta década), em meio a uma sociedade tecnológica e global caracterizada pela multiplicidade de linguagens e de culturas, que salienta a necessidade de se conhecer e de se respeitar a pluralidade cultural, assim como de se conhecer e de se aprender a escrever e a ler as novas linguagens - os hipertextos e os textos multimodais.

Como assevera Rojo (2013),

o conceito de multiletramentos, articulado pelo Grupo de Nova Londres, busca justamente apontar, já de saída, por meio do prefixo "multi", para dois tipos de "múltiplos" que as práticas de letramento contemporâneas envolvem: por um lado, a multiplicidade de linguagens, semioses e mídias envolvidas na criação de significação para os textos multimodais contemporâneos e, por outro, a pluralidade e a diversidade cultural trazidas pelos autores/leitores contemporâneos a essa criação de significação [...] (ROJO, 2013, p. 14, grifos da autora).

Embora os novos estudos sobre o letramento tenham reconhecido a relevância da cultura e de sua pluralidade ${ }^{2}$ para a constituição do sujeito e de suas práticas de letramento, bem como tenham observado a pluralidade de linguagens ${ }^{3}$, mantiveram (e ainda mantêm) o termo "práticas de letramento", havendo, a nosso ver, necessidade de abertura/avanço para uma concepção de "práticas de multiletramentos".

Certamente, as práticas de letramentos não deixaram de existir, porém, muitas práticas ultrapassaram o "letramento" (o mero apontamento dos múltiplos letramentos) e abarcaram "os multiletramentos" (as multiplicidades cultural e linguística), tornando-se, assim, "práticas multiletradas".

Sobre o contraponto entre o letramento e os multiletramentos, importa reavivarmos as ponderações de Rojo (2012), quando afirma que

diferentemente do conceito de letramentos (múltiplos), que não faz senão apontar para a multiplicidade e a variedade de práticas letradas, valorizadas ou não nas sociedades em geral, o conceito de multiletramentos - é bom enfatizar - aponta para dois tipos específicos e importantes de multiplicidade presentes em nossas sociedades, principalmente urbanas, na contemporaneidade: a multiplicidade cultural das populações e a multiplicidade semiótica de constituição dos textos por meio dos quais ela se informa e se comunica (ROJO, 2012, p. 13).

\footnotetext{
${ }^{2}$ Não à toa, os novos estudos sobre o letramento trabalham com o conceito antropológico de letramento.

${ }^{3}$ Street $(1998,2001)$ apud Carvalho $(2012$, p. 228) já fazia menção a uma "nova ordem de comunicação", em que a linguagem era tida como um amplo sistema semiótico.
} 
No contexto multiletrado contemporâneo, a leitura não é a mesma de alguns anos atrás. Lê-se de forma não linear textos também não lineares - falamos de hipertextos. A escrita também se alterou. Na escrita, não nos limitamos mais às letras. Usamos várias outras linguagens (modos ou semioses) na constituição dos textos, como imagem e arranjos de diagramação. As barreiras tradicionalmente impostas entre leitor e escritor são rompidas, de modo que um é, ao mesmo tempo, o outro.

A cultura torna-se mestiça, e não se justifica mais a eleição de uma cultura superior "A cultura". Cada sujeito possui e/ou constrói sua própria coleção cultural.

Dessa maneira, revelam-se os multiletramentos cujas características principais podem ser encontradas em sujeitos que se engendram em interações múltiplas muito mais colaborativas, em que as relações se hibridizam, fraternizam-se e se diluem na confluência de produções linguísticas/discursivas também mistas e "fronteiriças", constituindo a diversidade de linguagens em diferentes formatos e a diversidade cultural existentes.

Tais caracteres permeiam, naturalmente, as práticas multiletradas - múltiplas cultural e linguisticamente -, de modo que, em nossa análise, não poderemos dispensá-las.

\section{Práticas de letramento no contexto analisado: alguns resultados}

Antes de trazermos à baila alguns resultados da pesquisa realizada, avaliamos ser relevante indicar, embora sucintamente, o contexto da pesquisa no qual adentramos, bem como explicitar o procedimento metodológico adotado.

Elegemos uma pesquisa de natureza qualitativa, sob a ótica de Deslauries e Kéristit (2012), buscando explorar informações de uma situação específica, de modo que pudessem fornecer explicações para a descrição e a interpretação de nosso objeto de estudo. Nessa perspectiva, investimos, ainda, em uma abordagem etnográfica, valorizando o "registro sistemático das informações e ações dos sujeitos pesquisados" (GHEDIN; FRANCO, 2011, p. 179), e adentramos, como observadores diretos, na sala de aula da disciplina "Laboratório de Vídeo I" de um Curso de Arte e Mídia de uma instituição pública do Estado da Paraíba.

Devidamente autorizados, observamos 18 (dezoito) alunos, 01 (um) professor e 01 (um) monitor durante 08 (oito) aulas, com duração de 4 (quatro) horas cada. Nossas observações se deram no período de 29 de abril a 17 de junho de 2015.

Além da observação em si, registrada em diário de campo, aplicamos dois questionários - um destinado ao docente e outro aos discentes e ao monitor.

Para os fins deste artigo, no entanto, deter-nos-emos na análise das práticas multiletradas dos alunos observadas em duas aulas: na primeira, ocorrida em 29 de abril de 2015 e, na penúltima, em 10 de junho do mesmo ano. Além disso, avaliaremos o questionário destinado aos discentes e respondido pelos mesmos, no dia 29 de abril de 2015.

Feitas essas ponderações mais genéricas, passamos à explicitação das práticas de letramento depreendidas da análise do material recortado, levando em conta, inicialmente, as práticas de letramento para, posteriormente, analisá-las à luz dos multiletramentos.

\subsection{Práticas de letramento dos discentes de arte e mídia: alguns exemplos}

Após aplicarmos o questionário com os sujeitos de nossa pesquisa, alunos da disciplina "Laboratório de Vídeo I", a fim de traçar o perfil deles, contabilizamos, uma a uma, cada produção citada pelos mesmos e selecionamos aquelas que foram mencionadas por mais discentes, de modo que pudéssemos, inicialmente, identificar o que eles produzem e, de certo 
modo, o que dizem sobre as práticas realizadas no contexto da sala de aula. Os resultados dessa análise podem ser visualizados na Fig. 1, em que apresentamos as produções realizadas por um total de 18 (dezoito) alunos.

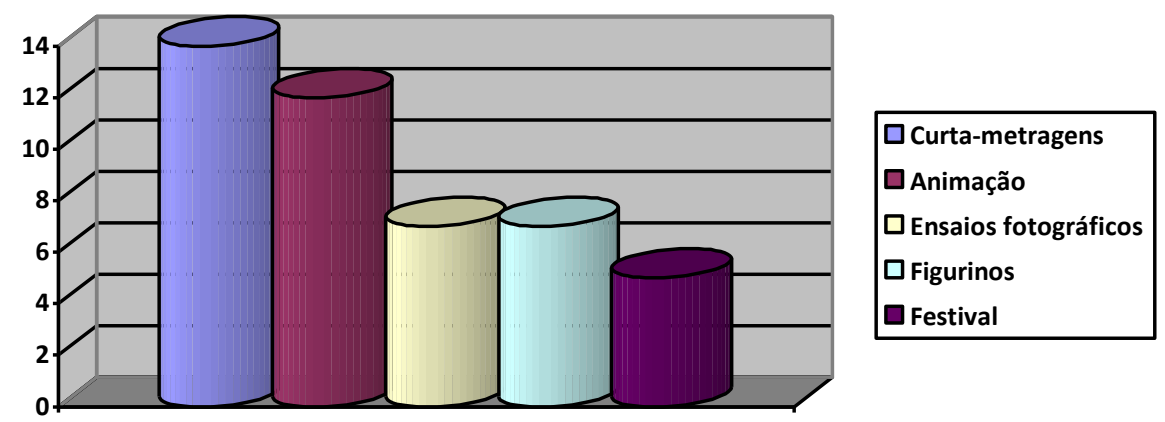

Figura 1: Principais produções mencionadas pelos alunos (total de 18)

Notemos que tais produções podem representar, indubitavelmente, práticas de letramento, haja vista além de envolverem usos da leitura e da escrita, possuírem significados para os sujeitos estudados. Percebemos, então, que a aprendizagem dessas produções revela formas relevantes e atuais de sua atuação profissional em sociedade. Dessa maneira, conhecer sobre o que eles produziram ou produzem oferece indícios que demonstram várias práticas envolvidas, que vão desde anotações até roteiros bem elaborados para atuações e filmagens efetivas.

Para além do que nos disseram, ao observarmos as aulas citadas e também eventos de letramentos ocorridos antes e depois dessas aulas, verificamos que os alunos da disciplina "Laboratório de Vídeo I" estão envoltos em práticas de letramento, denominadas por nós no âmbito deste estudo, acadêmicas e não acadêmicas. Essas práticas estão carregadas de significados, tanto para a vida estudantil (contexto específico do ambiente universitário, incluindo a sala de aula) quanto para a vida social (contexto social e cultural geral que circulam) desses sujeitos.

A partir da observação das aulas dos dias 29 de abril e 10 de junho de 2015, pudemos constatar a ocorrência das seguintes práticas letradas:

- Práticas de letramento não acadêmicas: uso de celular, com suas várias funcionalidades, durante a aula.

- Práticas de letramentos acadêmicas: análise de filmes; produção de resumos e seminários.

Considerando a importância social do celular na vida dos sujeitos contemporâneos, do qual, cada vez mais, as pessoas fazem usos diversos com finalidades várias, e "[...] a forma como os habitantes das cidades se comportam em ambientes públicos e privados mudou com o surgimento de celulares [...]" (SANTAELLA, 2007, p. 134), analisaremos o uso de celular em sala de aula, com sua pluralidade de funções.

\section{Uma prática multiletrada em foco}

De início, "a cultura do celular", no grupo, causou-nos estranheza. Afinal, em nossa cultura, os alunos são orientados a desligarem ou a deixarem seus celulares em modo silencioso durante a aula. 
No grupo estudado, no entanto, e é o que nos importa, os celulares, "como membros que se estendem àqueles corpos", ficam sobre as carteiras, à inteira disposição do proprietário, sendo usados constantemente e de diversas formas - para atenderem ligações, para enviarem mensagens pelo WhatsApp, para acessarem redes sociais, dentre outros.

Diante desse cenário, o professor manteve-se, a todo instante, indiferente ${ }^{4}$, o que nos levou a concluir que estamos diante de uma prática de letramento, no caso, não acadêmica, que encarta vários significados para os sujeitos estudados, a exemplo de meio de contato grupal durante a aula, sem uso de fala ou de "bilhetinhos" - durante as aulas observadas, percebemos os alunos usando os celulares ao mesmo tempo.

Sabido que se trata de uma prática de letramento, incontestavelmente, questionamonos se não seria uma prática de multiletramentos.

Vamos, então, tomando como base as características dos multiletramentos elencadas por Rojo (2012), e aqui reformuladas em forma de perguntas, cujas respostas nos permitirão vislumbrar o uso do celular como uma prática multiletrada ou não, de maneira que facilite o nosso entendimento sobre que práticas multi(letradas) esses sujeitos vivenciam. Vejamos, então:

- Essa prática é interativa e colaborativa?

Sim, sem dúvidas. Vimos os alunos utilizarem o celular como meio de interação e de colaboração com o outro - conversa em WhatsApp, por exemplo;

- Ela fratura e transgride as relações de poder estabelecidas?

Sim, inquestionavelmente. Em uma sala de aula de ensino tradicional, o uso de celulares seria, provavelmente, restringido. Sendo que, no grupo estudado, tal prática demonstrouse natural, comum em todos os dias de observação;

- É híbrida, fronteiriça, mestiça?

Sim, com certeza. O uso de celular abarca o uso de várias linguagens, de vários modos, de várias mídias e culturas. O WhatsApp, por exemplo, tão usado pelos discentes, sabidamente, é meio multimodal e hipermidiático. Nele, circulam/constroem-se vídeos, imagens, textos etc.

Assim, atendidas as características dos multiletramentos, o uso de celulares pelos alunos constitui saliente prática multiletrada do grupo estudado, a qual, sendo caracterizadora da sociedade da informação, ultrapassa "as paredes da sala de aula". O celular e a comunicação que ele viabiliza estão no mundo também. Precisamos dar ênfase, ainda, às práticas empreendidas pelos sujeitos no contexto acadêmico, seja para escrever ou ler a diversidade de linguagens que se interceptam na configuração de tudo que precisam produzir. Essas práticas vão além da mera decodificação de uma mensagem e alcançam os usos que representam o sujeito que é autor e coautor de produções individuais e coletivas.

\section{Considerações finais}

Ao longo deste artigo, retomamos a teoria que embasa as práticas de letramento novos estudos sobre o letramento -, bem como a que viabiliza a defesa de práticas de multiletramentos - teoria dos multiletramentos -, visando embasamento teórico para investigar práticas (multi)letradas vivenciadas pelos alunos da disciplina "Laboratório de Vídeo I" de um Curso de Arte e Mídia de uma instituição pública da Paraíba.

\footnotetext{
${ }^{4} \mathrm{Na}$ aula do dia 29 de maio de 2015, por exemplo, um aluno atendeu ao telefone na sala, mas o professor seguiu com a aula, sem perder o foco do conteúdo que estava trabalhando.
} 
Feito isso, expomos, como resultado de uma pesquisa etnográfica, algumas práticas letradas, como produção de resumo, figurinos, animação etc., e analisamos o uso de celulares em sala de aula.

Ao final, constatamos que o uso de celular constitui prática multiletrada, e não apenas letrada, marcada pela hibridização de linguagens e de culturas. Tal fato ganha realce ainda mais quando consideramos a sociedade contemporânea, a qual, sendo claramente diferenciada do mundo moderno (positivista), é um caldeirão de misturas que requer práticas híbridas, mestiças, fronteiriças, interativas, colaborativas e transgressivas - práticas multiletradas!

É relevante destacar, por fim, que essas práticas podem acarretar impactos no processo pedagógico de formação desses alunos, tendo em vista que vivenciamos avanços tecnológicos que interferem de modo avassalador na vida das pessoas. O celular, por exemplo, já pode ser utilizado para gravar um filme inteiro e, certamente, caberá a um Diretor em arte e mídia a necessidade de ter conhecimento sobre como lidar com essa prática. Enfim, embora essa discussão ultrapasse os objetivos deste trabalho, cabem, aqui, alguns questionamentos para pesquisas futuras e para aprofundamento das discussões: qual a natureza ideológica dessa prática, de modo que oriente os indivíduos a produções críticas efetivas? Que usos pedagógicos podem ser implementados para que professores e alunos façam uso do celular, articulando a diversidade de culturas e de linguagens existentes?

\section{Referências}

CARVALHO, C. Práticas de letramento e a construção discursiva das identidades no contexto virtual de ensino do português. In.: MAGALHÃES, I. (Org.). Discursos e Práticas de Letramento. Campinas/SP: Mercado de Letras, 2012, p. 227-268.

DESLAURIES, J-P.; KÉRISTIT, M. O delineamento da pesquisa qualitativa. In: POUPART et al (Org.). A pesquisa qualitativa: enfoques epistemológicos e metodológicos. Petropólis: Vozes, 2012, p. 127-153.

GHEDIN, E; FRANCO, M. A. Etnografia como paradigma de construção do processo de conhecimento em educação. In.: Questões de Método na construção da pesquisa em educação. 2. ed. São Paulo: Cortez, 2011, p. 177-231.

LOPES, L. P. da M. Introdução: Fotografias da Linguística Aplicada brasileira na modernidade recente: contextos escolares. In.: . Linguística Aplicada na modernidade recente. São Paulo: Parábola, 2013, p. 15-37.

ROJO, R. Gêneros discursivos do círculo de Bakhtin e multiletramentos. In: Escola Conectada: os multiletramentos e as TICS. São Paulo: Parábola, 2013, p. 13-36.

Pedagogia dos Multiletramentos. In.: ROJO, R.; MOURA, E. (Orgs.). Multiletramentos na escola. São Paulo: Parábola Editorial, 2012, p. 11-31.

Letramento(s): Práticas de letramento em diferentes contextos. In.:

Letramentos múltiplos, escola e inclusão social. São Paulo: Parábola Editorial, 2009, p. 95121. 
SOARES, M. Práticas de Letramento e implicações para a pesquisa e para políticas de alfabetização e letramento. In.: MARINHO, M. (Org.). Cultura escrita e letramento. Belo Horizonte: UFMG, 2010.

STREET, B.; CASTANHEIRA, M. L. Práticas e eventos de letramento. Disponível em: http://ceale.fae.ufmg.br/app/webroot/glossarioceale/verbetes/praticas-e-eventos-deletramento. Acesso em: 01 de julho de 2015, às 10h00min.

STREET, B. Letramentos Sociais: Abordagens críticas do letramento no desenvolvimento, na etnografia e na educação. São Paulo: Parábola Editorial, 2014.

Eventos de letramento e práticas de letramento: teoria e prática nos Novos Estudos do Letramento. In.: MAGALHÃES, I. (Org.). Discursos e Práticas de Letramento. Campinas/SP: Mercado de Letras, 2012, p. 69-92.

Os novos estudos sobre o letramento: histórico e perspectivas. In.: MARINHO, M.; CARVALHO, G. T. (Orgs.). Cultura escrita e letramento. Belo Horizonte: Editora UFMG, 2010, p. 33-53.

Recebido em: dezembro de 2015.

Aprovado em: março 2016. 